Pak. j. sci. ind. res. Ser. A: phys. sci. 201356 (1) 1-5

\title{
FTIR - A Didactic Approach for the Study of Humic Acid - Chromium Chelation During the Environmental Remediation
}

\author{
Zakiuddin Ahmed $^{\text {a*, }}$, Syed Arif Kazmi ${ }^{\mathrm{b}}$, Mateen Muhammad Khana, \\ Gulzar Hussain Jhatial ${ }^{\mathrm{a}}$ and Nadir Buksh ${ }^{\mathrm{a}}$ \\ ${ }^{a}$ Fuel Research Centre - PCSIR, Off University Road, Karachi-75280, Pakistan \\ ${ }^{b}$ Department of Chemistry, University of Karachi, Karachi-75270, Pakistan
}

(received December 15, 2011; revised April 12, 2012; accepted May 17, 2012)

\begin{abstract}
The present study uses infra-red spectroscopy as a didactic approach to characterize the chromiumhumic acid interaction. Shifts of the characteristic carboxylate peaks in the IR spectrum of humic acid upon its interaction with chromium are noted. These changes have been interpreted to conclude that binding of chromium to humic acid is through these groups. An analytical grade humic acid was used for this study. It was also concluded that at the moderate $\mathrm{pH}$ i.e 8.5 all the waste chromium ions were cleared from waste water controlling the water $\mathrm{pH}$.
\end{abstract}

Keywords: IR study, humic acid, chelation, chromium binding

\section{Introduction}

Humic acids (HA) isolated from coals using an alkaline solution, are very complexed organic macromolecules with acid functional groups, primarily carboxylic acids and phenols as well as carbonyls, amines, aromatic and aliphatic carbons. Humic acid binds heavy metals due to its higher content of oxygen-containing functional groups (Casas and Martin, 1997), which can form stable complexes with metals as $\mathrm{Cu}(\mathrm{II}), \mathrm{Hg}(\mathrm{II}), \mathrm{Cd}(\mathrm{II}), \mathrm{Cr}(\mathrm{III})$ etc. This binding capacity has been demonstrated in several studies (Yasser et al., 2011; Dragan and Fitch, 1998). It is found that humic substances can reduce the concentration of free metals ions in waters (Stackhouse and Benson, 1989).

In a reported experiment (Holman et al., 2002), the lead complex band shift for $\mathrm{C}=\mathrm{O}$ from $1670 \mathrm{~cm}^{-1}$ for the free ligand to $1537 \mathrm{~cm}^{-1}$ and another similar experiment (Tharanitharan and Srinivasan, 2009) was designed in which the FTIR spectrum of free EDTA was compared with that of lead EDTA identifying the changes in $\mathrm{C}=\mathrm{O}$ produced by EDTA-lead complexation. Many more experiments involving the synthesis and study of the FTIR spectra of carbonylcontaining organometallic compounds are now proposed as laboratory experiments. The binding sites for $\mathrm{Cu}, \mathrm{Cd}$, and $\mathrm{Pb}$ are strongly related to the humic substance content of extracellular polymers (ECP) in activated sludge (Guibaud et al., 2003). The

*Author for correspondence; E-mail: frc_pcsir@hotmail.com stability of ECP-metal complexes followed the order $\mathrm{Cd}>\mathrm{Pb} \sim \mathrm{Cu}$ and the metallic ions are bonded to acidic groups of humic acid (Boyd et al., 1981). In that way, carboxylate has been identified as the group mainly responsible for chelation between humic substances and metallic ions (Holman et al., 2002). This is because lone-electron pairs on the oxygen atom can produce a coordinate bond with the empty d-orbitals in heavy metals. This chelation produces changes in position and intensity of the characteristic IR absorption bands in the ranges around $1700 \mathrm{~cm}^{-1}$ and $1600 \mathrm{~cm}^{-1}$.

Complexes between 2,5-dihydroxybenzoate and heavy metals including $\mathrm{Cd}$ (II) using IR and electronic spectroscopy showed octahedral coordination with the heavy metal bound to two monodenate carboxylate groups in the trans position and 4 water molecules (Micera and Erre, 1992). On the basis of the latter, one hypothesis that can be established is that carboxyl and carboxylate groups in the humic material are responsible for $\mathrm{Cd}$ complexation, which is evidenced by displacements of the symmetric and asymmetric stretching vibration of the $\mathrm{COOH}$ and $\mathrm{COO}^{-}$groups.

A better understanding of interaction between metalorganic ligand is one of the key issues in soil science today.

Advanced analytical techniques, such as atomic absorption spectrometry alone cannot play proper role in the study of heavy metal interactions with coal constituents. Therefore, infrared studies may support in the understanding and reviewing of interior of 
molecular lattice by the help of characteristics IR absorption spectral bands giving clear picture of how the metal ions are retained by humic acid.

In an earlier study its potential use for chromium removal from waste waters has been discribed. For present study humic acid isolated from Lakhra lignite coal was used. Chelation between $\mathrm{Cr}^{3+}$ and HA was studied using FTIR spectroscopy to identify the functional groups involved in complex formation, possible multidentate character of the ligands, and the effects of $\mathrm{pH}$ as well as addition of increasing amounts of $\mathrm{Cr}$ (III) on the IR bands associated with carbonyl symmetric and asymmetric stretching.

\section{Materials and Methods}

Material. Analytical grade humic acid standard from Sigma Aldrich Company was used.

Preparation for FTIR spectra. At the first step, the effect of $\mathrm{pH}$ on the humic acid FTIR spectra was determined.Two samples of dried HA $(100 \mathrm{mg})$ were placed in test tubes. The first tube was filled with 20 $\mathrm{mL}$ of distilled water. To the second tube $10 \mathrm{~mL}$ of distilled water was added and the $\mathrm{pH}$ was adjusted to 7.5 with $0.1 \mathrm{M} \mathrm{NaOH}$. Additional water was added to a final volume of $20 \mathrm{~mL}$. Both tubes were agitated for $1 \mathrm{~h}$ : centrifuged and the supernatant was discharged. The solid residue was washed three times with distilled water and dried in an electric oven at $40{ }^{\circ} \mathrm{C}$ for $12 \mathrm{~h}$. FTIR spectra were then recorded.

Humic acid chromium chelation. The effect of $\mathrm{Cr}^{3+}$ chelation with humic acid was determined through FTIR spectra. Into five test tubes, $100 \mathrm{mg}$ of HA was placed along with $10 \mathrm{~mL}$ of $0.0002 \mathrm{M}, 0.002 \mathrm{M}, 0.02 \mathrm{M}, 0.2$ $\mathrm{M}$ and $0.5 \mathrm{M}$ Chromium sulphate $\mathrm{Cr}_{2}\left(\mathrm{SO}_{4}\right)_{3}$ solution, respectively. Suspensions were agitated for $12 \mathrm{~h}$, and supernatant was removed after centrifugation. These supernatants were then tested for reduction of $\mathrm{Cr}^{3+}$ ions at atomic absorption spectrometer (Table 1). Solid residues were washed three times with distilled water and dried in an electric oven at $40{ }^{\circ} \mathrm{C}$ for $12 \mathrm{~h}$. All infrared spectra of $\mathrm{HA}$ and $\mathrm{Cr}-\mathrm{HA}$ recorded using $\mathrm{KBr}$ discs (ca. 1\%) at Thermo-Nicolet Model 6700 FTIR in the region of 3500 to $400 \mathrm{~cm}^{-1}$ at a $2 \mathrm{~cm}^{-1}$ resolution.

\section{Results and Discussion}

The possible models explaining how binding takes place involve functional groups (Table 2-3), coordinate bonds, electronic attractions between positive and negative species, chelation and surface electric charge of colloidal materials.

Oxygen containing functional groups i.e. carboxylic acids and carboxylates are mainly responsible for this chelation in large number of mono and multidentate ligands. These compounds can be synthesized and, by observing the positions, shapes and displacements of their characteristic absorption bands around 1800 and $1600 \mathrm{~cm}^{-1}$, can predict possible coordination mode.

Table 4-5 show actual picture of the active functional groups involved and describe their participation through different respective bands for expected chelation. The results identified the most important features of the FTIR spectra of humic acids at pH 5.5 (Fig1a), which are (a) an intense and broad band between 3500 and 3100 $\mathrm{cm}^{-1}$ due to the stretch of various hydroxyl and N-H

Table 1. Complexation(Ahmed et al., 2006) in $\mu \mathrm{g} / \mathrm{mL}$ of $\mathrm{Cr}^{3+}$ by humic acid (pH- 3.53 to 8.5 )

\begin{tabular}{lllll}
\hline \hline $\left.\mathrm{Cr}^{3+}\right]$ & {$\left[\mathrm{Cr}^{3+}\right]$} & $\Delta\left[\mathrm{Cr}^{3+}\right]$ & $\begin{array}{l}\mathrm{Cr}^{3+} \\
\text { adsorbed } \\
\text { initial }\end{array}$ & final
\end{tabular}

Table 2. Elemental composition of humic acid

\begin{tabular}{ll}
\hline \hline Element & Humic acid $(\mathrm{wt} \%)$ \\
\hline $\mathrm{C}$ & $53.6-58.7$ \\
$\mathrm{H}$ & $3.2-6.2$ \\
$\mathrm{~N}$ & $0.8-5.5$ \\
$\mathrm{O}$ & $32.8-38.3$ \\
$\mathrm{~S}$ & $0.1-1.5$ \\
\hline \hline
\end{tabular}

Table 3. Estimated functional groups in humic acid (m. mol/g).

\begin{tabular}{ll}
\hline \hline Functional group & Humic acid \\
\hline Total acidic groups & $5.6-8.9$ \\
Carboxyl $\mathrm{COOH}$ & $1.5-5.7$ \\
Phenolic $\mathrm{OH}$ & $2.1-5.7$ \\
Alcoholic $\mathrm{OH}$ & $0.2-4.9$ \\
Quinoid $/$ keto C $=\mathrm{O}$ & $0.1-5.6$ \\
Methoxy $\mathrm{OCH}_{3}$ & $0.3-0.8$ \\
\hline \hline
\end{tabular}




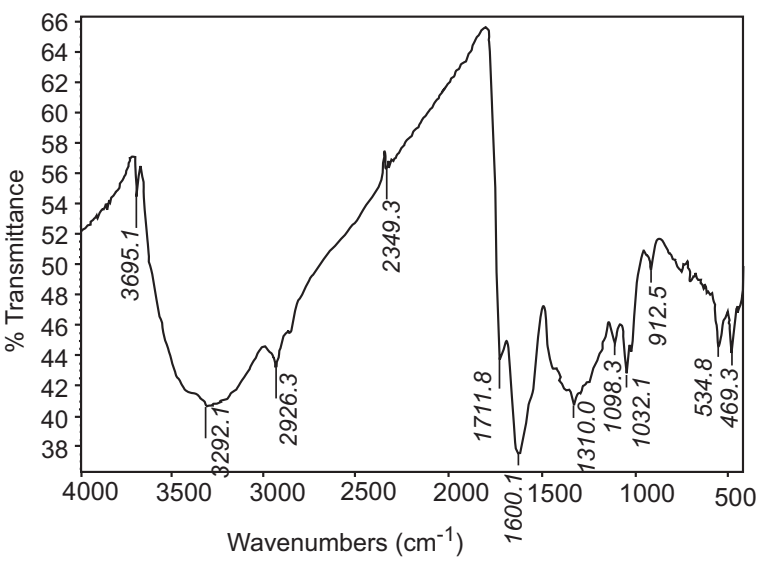

Fig. 1a. Humic acid at $\mathrm{pH} 5.5$.

functional groups; (b) peaks of variable intensity between 2930 and $2855 \mathrm{~cm}^{-1}$ and between 2855 and $2850 \mathrm{~cm}^{-1}$, which are associated with aliphatic $\mathrm{C}-\mathrm{H}$ symmetric and asymmetric stretching; (c) absorption bands at 1711.8 $(\mathrm{COOH}), 1600.1\left(\mathrm{v}_{\mathrm{S}}\left(\mathrm{COO}^{-}\right)\right)$and $1310 \mathrm{~cm}^{-1}$ ( $\mathrm{a}(\mathrm{COO})$ and $\mathrm{OH}$ in $\mathrm{COOH}$ group) which indicated the presence of both symmetric and asymmetric stretching vibrations of $-\mathrm{COOH}$ and $-\mathrm{COO}^{-}$and (d) an asymmetric stretching vibration around 1032 and $912.5 \mathrm{~cm}^{-1}$, which indicated the presence of skeletal $\mathrm{C}-\mathrm{C}$ vibrations. Spectra have also been reported (Micera and Erre, 1992; Boyd et al., 1981) for humic substances, found absorption bands for carboxylic acids and carboxylates.

The FTIR spectrum suggested the existence of both dissociated and undissociated forms of carboxylic acids when humic acid are at pH 5.5 (Fig. 1a).

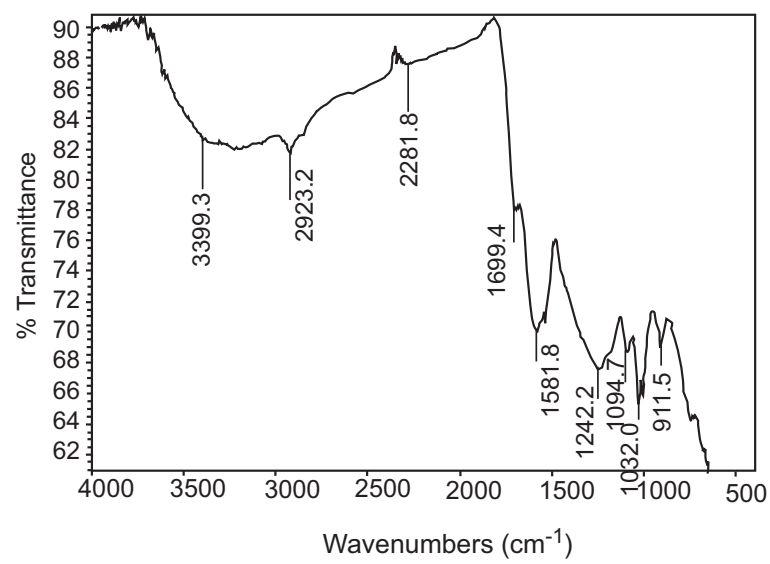

Fig. 1b. Humic acid Spectra pH 7.5.

Figure $1 \mathrm{~b}$ indicates changes observed in FTIR spectra providing evidence for the shifting of the equilibrium, on increasing $\mathrm{pH} 5.5$ to $\mathrm{pH} 7.5$. The intensity of the $1711.8 \mathrm{~cm}^{-1}$ band is reduced as ionized carboxyl groups increased. A displacement is also observed in the asymmetric vibration band of the carboxylate anion from 1600.1 to $1581.8 \mathrm{~cm}^{-1}$ with a parallel shift to frequencies (1310 to $1242.2 \mathrm{~cm}^{-1}$ and 1098.3 to $1094.7 \mathrm{~cm}^{-1}$ ) for $\mathrm{C}-\mathrm{O}$ stretch. All the experiments were conducted quantitatively with the same amount of humic acid in each case to compare the intensities of the bands.

Figure 2-7 reflect the effect of $\mathrm{Cr}^{3+}$ addition on the FTIR spectra of humic acids suspension, indicating similar changes to those produced by $\mathrm{pH}$. The absorption band at $1700 \mathrm{~cm}^{-1}$ is progressively displaced to lower frequencies until it disappeared at the highest $\mathrm{Cr}^{3+}$ concentration.

Table 4. IR spectral assignments for the humic acid and Cr-humic acid Complex

\begin{tabular}{|c|c|c|}
\hline Compounds & $\begin{array}{l}\text { Peaks of Humic acid and } \mathrm{Cr}^{3+} \\
\text { complexes }\left(\mathrm{cm}^{-1}\right)\end{array}$ & Tentative assignments \\
\hline & $3500-3100$ & Due to presence of various $\mathrm{OH}$ groups \\
\hline $\begin{array}{l}\text { Humic acid } \\
\text { (HA) at pH 5.5) }\end{array}$ & $\begin{array}{l}2926.3-2855 \text { and } 2855-2850 \\
1711.8,1600.1 \text { and } 1310 \\
1032 \text { and } 912.5\end{array}$ & $\begin{array}{l}\text { Aliphatic } \mathrm{C}-\mathrm{H} \text { stretch } \\
-\mathrm{COOH},-\mathrm{COO}^{-} \text {and } \mathrm{C}=\mathrm{O} \\
\mathrm{C}-\mathrm{C} \text { skeleton, } \mathrm{Si}-\mathrm{O} \text { silicate impurities }\end{array}$ \\
\hline $\begin{array}{l}\text { Humic acid HA } \\
\text { at } \mathrm{pH} 7.5\end{array}$ & $\begin{array}{l}1600.1-1581.8 \\
1310-1242.2 \\
1098.3-1094.7\end{array}$ & $\begin{array}{l}-\mathrm{COOH} \text { and } \mathrm{C}=\mathrm{O} \text { vibration } \\
-\mathrm{COOH} \text { and } \mathrm{C}=\mathrm{O} \text { vibration } \\
\mathrm{C}-\mathrm{O}\end{array}$ \\
\hline $\begin{array}{l}\text { Chromium - HA } \\
\text { complex }\end{array}$ & $\begin{array}{l}\text { Band at } 1700 \text { disappeared at } \\
\text { higher concentrations of } \mathrm{Cr}^{3+} \\
\text { Shifting of } 1586.4-1581.2\end{array}$ & $\begin{array}{l}\text { Due to complexation } \\
\text { Ionization of carboxylic acid occurred }\end{array}$ \\
\hline $\begin{array}{l}\mathrm{Cr}^{3+} \text { concentration } \\
0.0002 \mathrm{M}-0.5 \mathrm{M}\end{array}$ & 1245.7 moved to 1251.4 and 1272.1 & $\begin{array}{l}\text { Complexing of higher concentration of } \mathrm{Cr}^{3+} \\
\text { Deformation vibration of } \mathrm{OH} \text { in } \mathrm{COOH} \\
\text { group and } v_{\mathrm{s}}\left(\mathrm{COO}^{-}\right)\end{array}$ \\
\hline
\end{tabular}




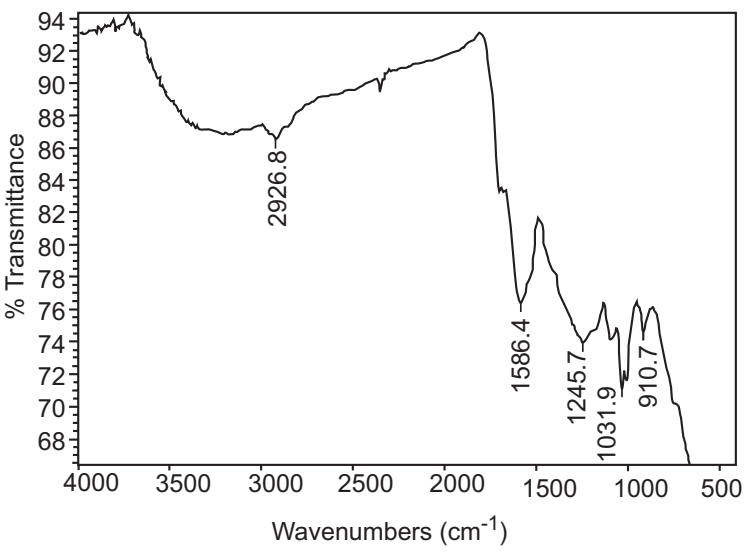

Fig. 2. Spectra IR for sample A-1 (Complexed with $0.0002 \mathrm{M} \mathrm{Cr}^{3+}$ )

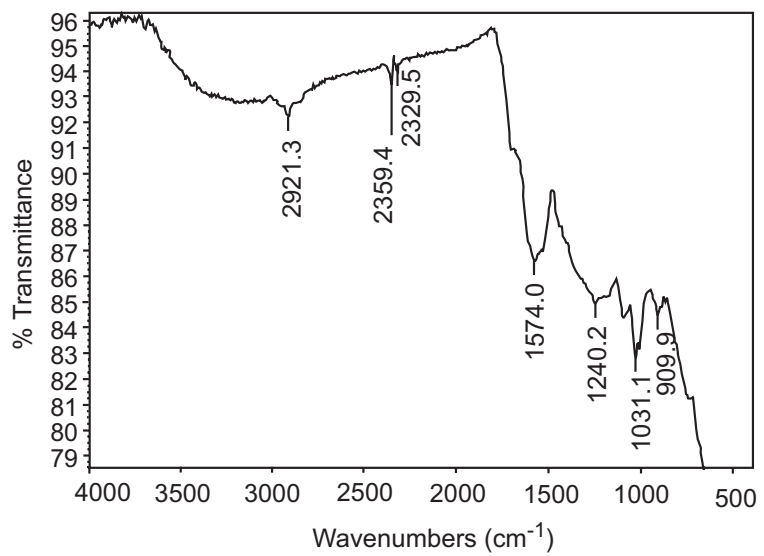

Fig. 4. Spectra of IR for Sample C-1 (Complexed with $0.02 \mathrm{M} \mathrm{Cr}^{3+}$ ).

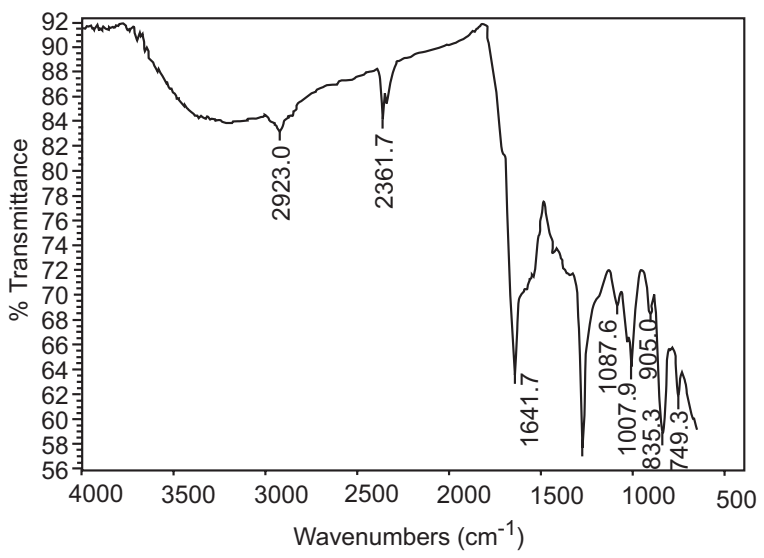

Fig. 6. Spectra IR for sample E-1 (Complexed with $\left.0.5 \mathrm{M} \mathrm{Cr}^{3+}\right)$.

Also, shifts from 1586.4 to $1581.2 \mathrm{~cm}^{-1}$ in $\mathrm{v}_{\mathrm{S}}\left(\mathrm{COO}^{-}\right)$, consistent with ionization of carboxylic acids, occurred. It is observed that both neutralization and metal complexation induced the conversion of $-\mathrm{COOH}$ to

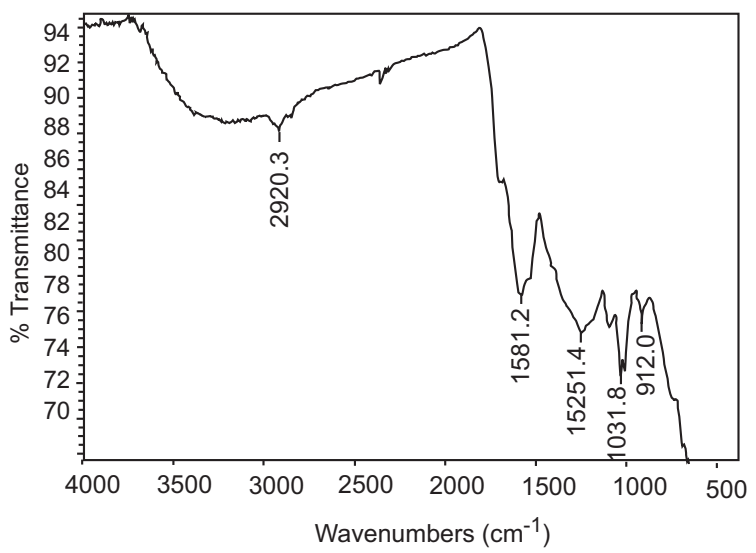

Fig. 3. Spectra IR for sample B-1 (Complexed with $0.002 \mathrm{M} \mathrm{Cr}^{3+}$ ).

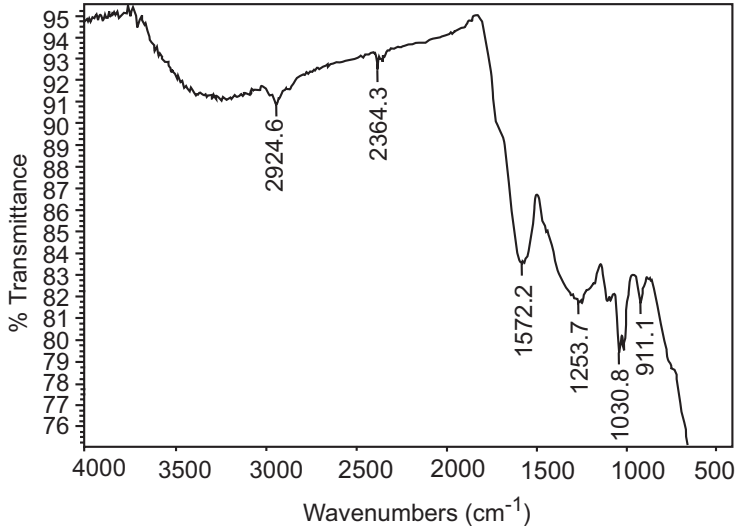

Fig. 5. Spectra of IR for Sample D-1 (Complexed with $0.2 \mathrm{M} \mathrm{Cr}^{3+}$ )

COO, is evidenced by the disappearance of the 1711.8 $\mathrm{cm}^{-1}$ band. The absorption band for the symmetric stretching vibration also changed but to a higher frequency. These results showed that,addition of $\mathrm{Cr}^{3+}$ in increased amounts, effectively, induced the ionization to the carboxylic acids followed by chromium coordination to the centre of negative charge (Table 1).

It is necessary to differentiate between the possible types of complexes between carboxylate and $\mathrm{Cr}^{3+}$. Separation between the asymmetric $\mathrm{va}_{\mathrm{a}}\left(\mathrm{COO}^{-}\right)$and symmetric $\mathrm{U}_{\mathrm{S}}\left(\mathrm{COO}^{-}\right)$stretching frequencies is related to the mode of complexation.

In monodentate complexes (I) the separation between $\mathrm{va}_{\mathrm{a}}\left(\mathrm{COO}^{-}\right)$and $\mathrm{v}_{\mathrm{S}}\left(\mathrm{COO}^{-}\right)$is larger than in uncomplexed carboxylate ion. On the other hand, in chelate complexes, the separation is smaller than in free carboxylate, and in structure III or bridging complexes, the separation is similar to that of uncomplexed carboxylate. If it is 
Table 5. Carboxylate stretching frequencies of $\mathrm{HA}$ at $\mathrm{pH} 7.5$ and $\mathrm{Cr}-\mathrm{HA}$

\begin{tabular}{lllll}
\hline \hline & $\begin{array}{l}\mathrm{vs}_{\mathrm{S}}\left(\mathrm{COO}^{-}\right) \\
\left(\mathrm{cm}^{-1}\right)\end{array}$ & $\begin{array}{l}\mathrm{va}\left(\mathrm{COO}^{-}\right) \\
\left(\mathrm{cm}^{-1}\right)\end{array}$ & $\begin{array}{l}\Delta \\
\left(\mathrm{cm}^{-1}\right)\end{array}$ & Structure \\
\hline HA $(\mathrm{pH}=7.5)$ & 1581.8 & 1242.2 & 339.6 & Uncomplexed \\
Cr-HA & 1641.7 & 1272.1 & 396.6 & Bidentate \\
\hline \hline
\end{tabular}

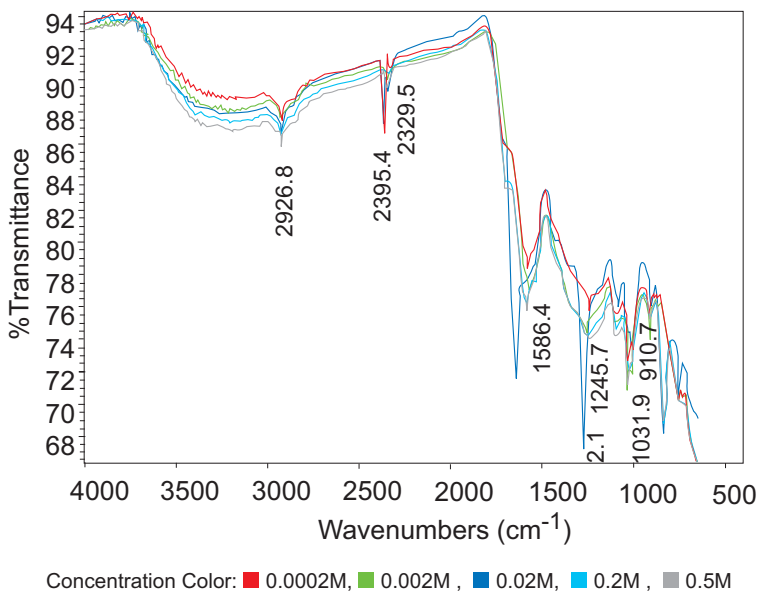

Fig. 7. Summarized spectra IR for humic acid chromium complex.

considered that at $\mathrm{pH} 7.5$ most of the carboxylic acid had been ionized, the absorption bands $\mathrm{va}\left(\mathrm{COO}^{-}\right)$ and $v_{\mathrm{S}}\left(\mathrm{COO}^{-}\right)$for HA are identified as uncomplexed (Table 2) where Cr-HA is referred to as a chromiumhumic acid complex. The separation value is lower in $\mathrm{Cr}-\mathrm{HA}$ than in the uncomplexed form; showing a bidentate character to the complexation between organic ligand and metallic ion (Boyd et al., 1981).

In this study, it was observed that HA adsorbed chromium ions. Ionic concentrations were reduced effectively, (Table 3) proportional to the initial concentration.

\section{Conclusion}

The present study uses infra-red spectroscopy as a didactic approach to characterize the chromium-humic acid interaction. Shifts of the characteristic carboxylate peaks in the IR spectrum of humic acid upon its interaction with chromium are noted. These changes have been interpreted to conclude that binding of chromium to humic acid is through these groups.

\section{References}

Ahmed, Z., Mir, S., Kazmi, A. 2006. Control of chrome pollution in tannery wastewaters with humic acids.
Pakistan Journal of Scientific and Industrial Research, 49: 143-146.

Boyd, S., Sonners, L.E.E., Nelson, D.W., 1981. Copper (II) and iron(III) complexation by the carboxylate group of humic acid. Soil Science Society of American Journal, 45: 1241-1242.

Casas, J. M., Martin, A. 1997. Simple preparation of Palladium (II) complexes and determination of their structures by infrared spectroscopy. Journal of Chemical Education, 74: 1327-1328.

Dragan, S., Fitch, A. 1998. Infrared spectroscopy determination of lead binding to ethylene diamine tetra acetic acid. Journal of Chemical Education, 75: 1018-1021.

Guibaud, G., Tixier, N., Bouju, A., Baudu, M. 2003. Relation between extracellular polymer's composition and its ability to complex $\mathrm{Cd}, \mathrm{Cu}$ and Pb. Chemosphere, 52: 1701-1710.

Holman, H.Y., Nieman, J.K.C., Sorensen, D.L., Miller, C.D., Martin, M.C., Borch, T., Mckiney, W.R., Sims, R.C. 2002. Catalysis of PAH biodegradation by humic acid shown in synchistron infrared studies. Environmental Science and Technology, 36: 1276-1280.

Micera, G., Erre, L.S. 1992. Interaction of metal ions with humic-like models-12. Adducts of Cobalt(II)and Nickel(II)-2,6-dimethoxybenzoates with heterocylic bases. In: Polyhedron, vol. 11, pp. 101-107, Elsevier, Amsterdam, The Netherland.

Stackhouse, R.A., Benson, W.H. 1989. Interaction of humic acid with selected trace metals influence of bio accumulation in daphnids. Environmental Toxicology and Chemistry, 8: 639-644.

Tharanitharan, V., Srinivasan, K. 2009. Removal of $\mathrm{Ni}$ (II) from water and wastewater using modified Duolite XAD-761 resin. Indian Journal of Chemical Technology, 16: 254-258.

Yasser, M., Ahmed, E. A., Shalaby and Nermeen, T. Shahnan. 2011. The use of organic and inorganic cultures in improving vegetative growth, yield characters and antioxidant activities of rodelle plants (Hibiscus sabdariffa L.). African Journal of Biotechnology, 10: 1988-1996. 